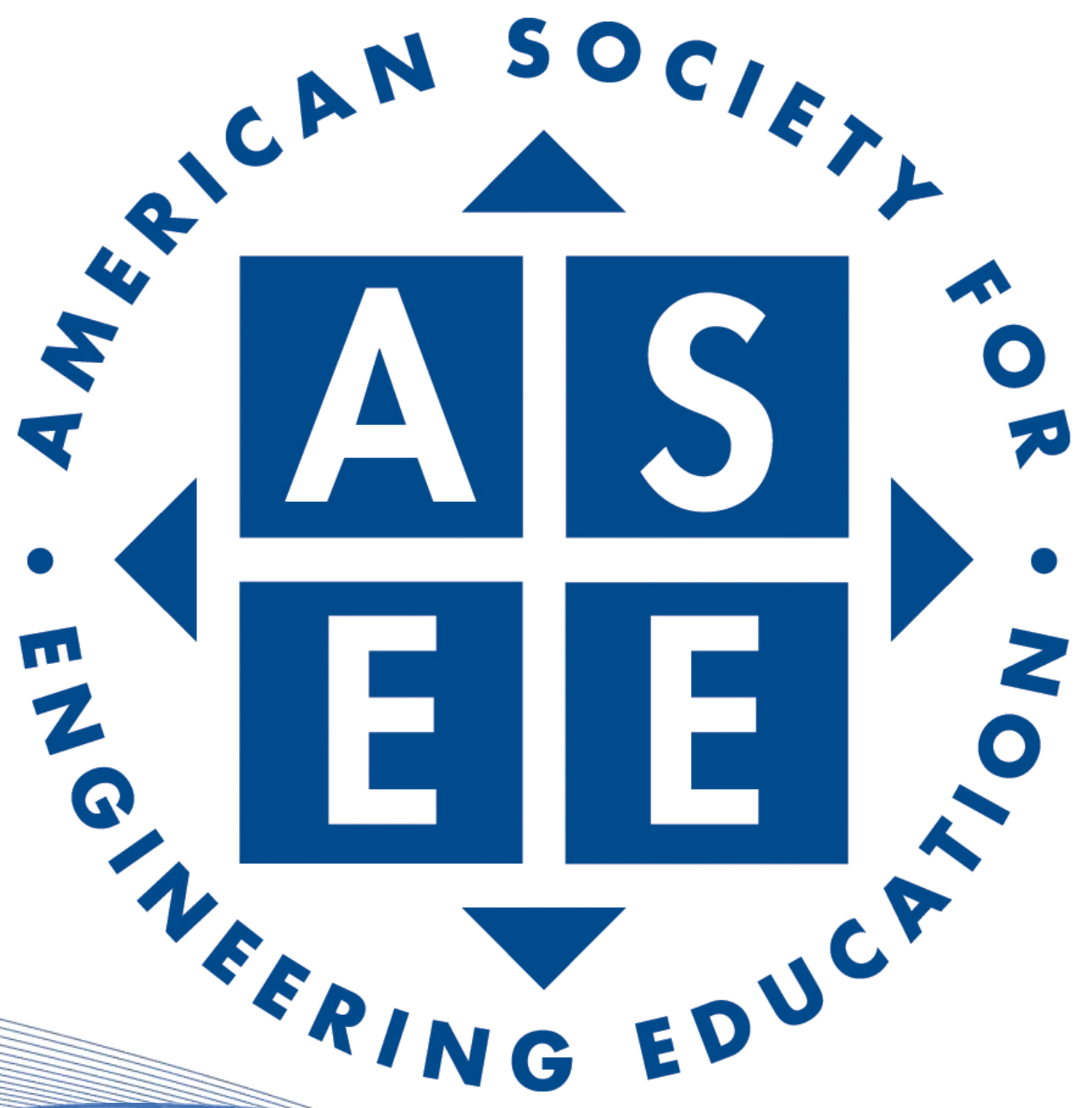




\section{EDC K-12 Committee}

\section{Update on CB/ASEE Committee Work on an "AP in Engineering"}

Darryll Pines, Chair

University of Maryland 


\section{The National Problem}

- In 2007, a Carnegie Foundation commission of distinguished researchers and public and private leaders concluded that "the nation's capacity to innovate for economic growth and the ability of American workers to thrive in the modern workforce depend on a broad foundation of math and science learning, as do our hopes for preserving a vibrant democracy and the promise of social mobility that lie at the heart of the American dream" 1 . However, the U.S. system of science and mathematics education is performing far below par and, if left unattended, will leave millions of young Americans unprepared to succeed in a global economy.

\section{- Reduction of the United States' competitive economic edge}

- Shrinking share of patents: Foreign competitors filed over half of U.S. technology patent applications in 2010.

- Diminishing share of high-tech exports:

- Lagging achievement of U.S. students

- The 2012 Program for International Student Assessment (PISA) ranks the United States as 23rd in Science, 30th in Math, and 20th in Reading Literacy out of 65 OECD education systems.

- In 2012, 54\% of high school graduates did not meet the ACT's college readiness benchmark levels in math, and $69 \%$ of graduates failed to meet the readiness benchmark levels in science.

- Essential preparation for all careers in the modern workforce

- Scientific and technological literacy for an educated society 


\section{National Academy Studies}

Call to Action

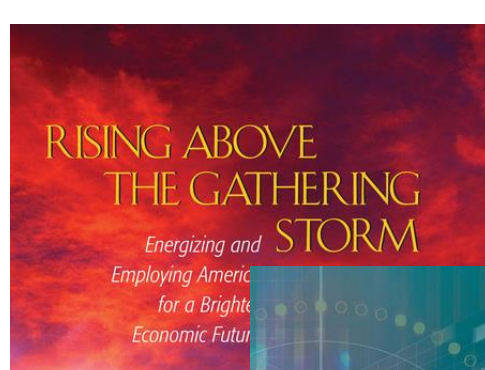

Framework/Standards Development
Implementation
Norm Augustine C. Dan Mote Linda Katehi
Curriculum

Development

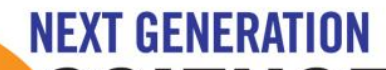

SCIENCE

STANDARDS

Stenderils tor $K-12$ Engineering in

Enginieering Etucar K-12 Education

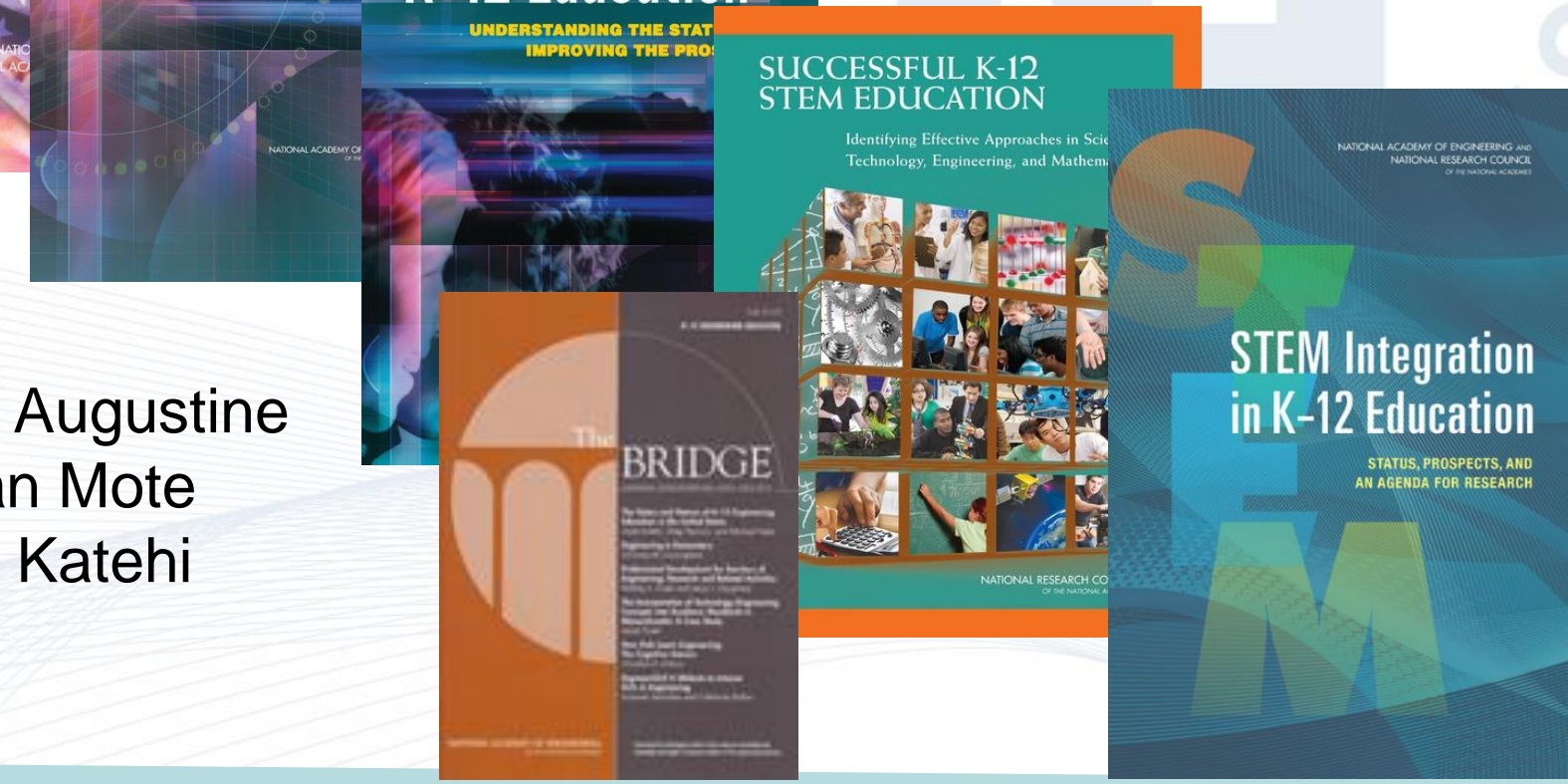

Assessments Evaluation 


\section{Motivation: Why now?}

- Overall college graduation levels in the United States have grown about 50 percent, but the number of engineering graduates has stagnated at around 130,000 (White House, 2011b). One Decade, One Million more STEM Graduates. Engineering graduates are $4.4 \%$ of total college graduates.

- National Priorities: In June, 2011, President Obama called for the training of 10,000 new American engineers a year (White House, 2011a).

- K-12 Standards. The January 2013 draft of the Next Generation Science Standards (NGSS) fully integrates engineering and technology into the structure of science education by raising engineering design to the same level as scientific inquiry at all levels of $\mathrm{K}-12$ education.

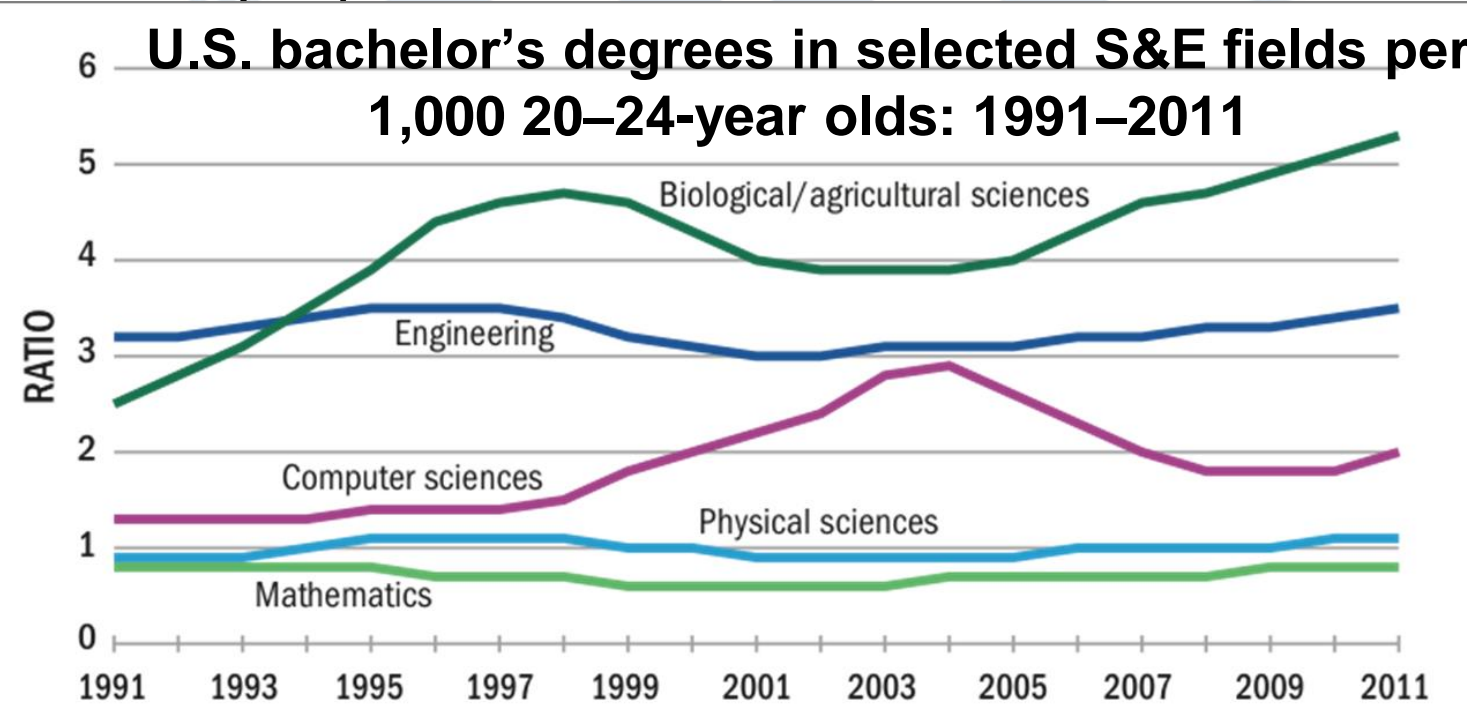




\section{Why an AP in Engineering?}

- AP Engineering would not only prepare students for success in four-year undergraduate engineering programs, it would also prepare Career and Technical Education (CTE) students to succeed in two-year programs.

- Surveys with Deans, Teachers, and Students support that there is significant interest in seeing an $\boldsymbol{A P}$ in Engineering offered and taught at the $\mathrm{K}-12$ level, preferably the junior year.

- The College Board is committed to developing the proposed new AP Engineering Exam to "reflect what we know about how students learn; build students' transferable, conceptual understanding and inquiry skills; and convey the content and unifying concepts of a discipline" (National Research Council 2002). 


\section{Additional Motivation for $\mathrm{AP} B$ in Engineering}

- $\mathrm{AP} \circledast$ - Parents and school systems view $\mathrm{AP} \AA$ as a pathway to college placement and acceptance.

- Weighted GPA - Honors, Gifted and Talented, and AP impact the weighted average

- Inclusion - Level the 'playing field' and increase diversity.

- Align Project-based Activities - "Formally recognize" individual student achievements in both formal and informal education settings. Aligns also with NGSS goals and objectives.

- Branding/Marketing-Brands the field of Engineering at the high school level and exposes students to possible opportunities that the field presents. 


\section{Basic College Board Criteria for an $\mathrm{AP} \AA$}

(1)Willingness of large numbers of US community colleges / colleges / universities to grant credit and exemption from an existing, undergraduate course.

(2)Teacher training models.

(3)Financial model to administer. 
What do National STEM/Policy Leaders think

\section{about an AP in Engineering?}

- "It is clearly a good idea if for no other reason than to give engineering a place among other serious academic subjects at the secondary school level that is not at the technician standard. The optics of this positioning in the eyes of the public is critical to engineering. It positions engineering to be fundamental to all highly educated people.", Dan Mote, President of National Academy, October 2013.

- "The problem solving, systems thinking, and teamwork aspects of engineering can benefit all students, whether or not they ever pursue an engineering career," said Linda Katehi, Chancellor of UC Davis, "A K-12 education that does not include at least some exposure to engineering is a lost opportunity for students and for the nation."

- "It is important to brand Engineering at the K-12 level to build pipeline for future engineering graduates," Thomas Kalil, Office of Science, Technology and Policy-OSTP

- "This is a great idea. Let me know how I can help," Pramod Kharonegar, Director of Engineering, NSF 


\section{Stagnate K-12 Pipeline: Secondarv Interest in Enaineerina}

8\% Of The 2012 Graduating SAT Takers Selected Engineering As A Major $\mathrm{n}=\mathbf{1 2 5 , 1 6 8}$

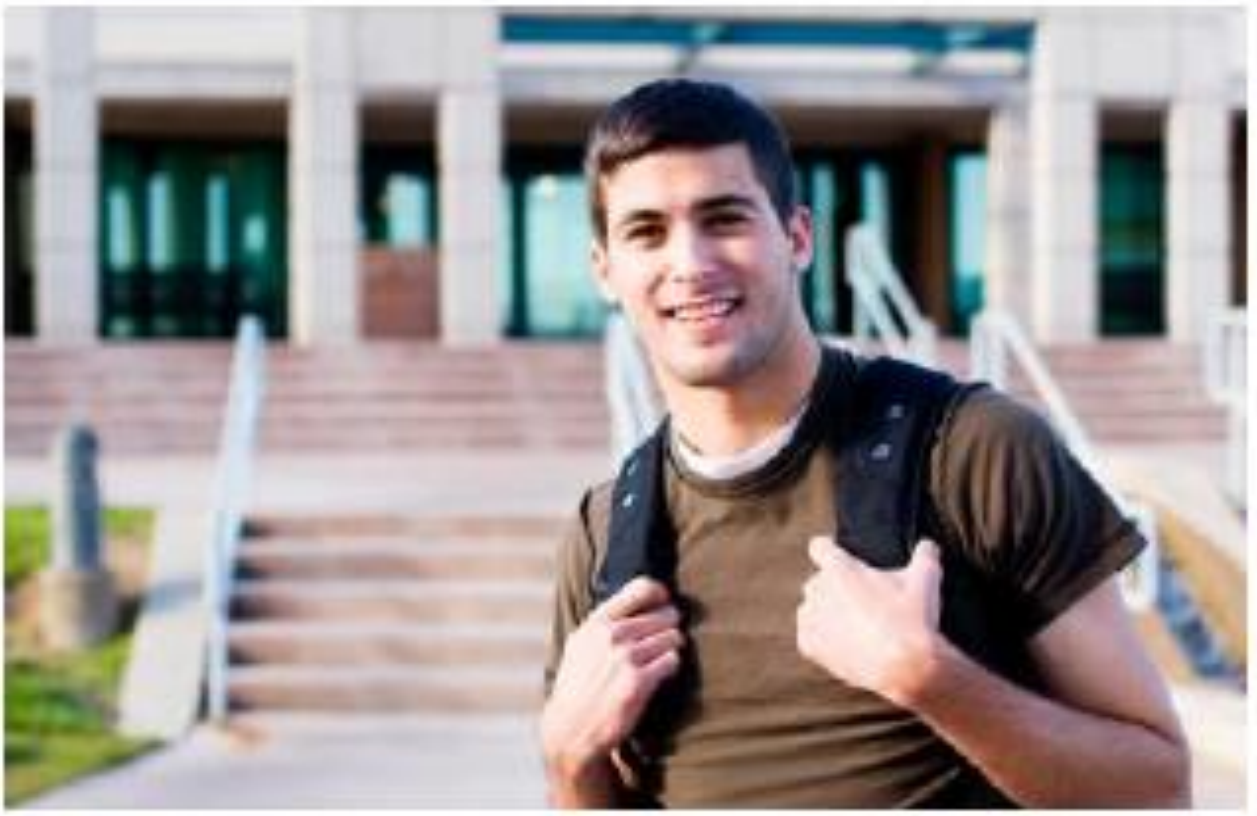

$83 \%$ Male
$53 \%$ White
Ave AP Courses Available $=12.30$
Ave AP Exams Taken $=2.38$
$72 \%$ Scoring 3-5 on AP STEM Exam
$71 \%$ Report a CUMGPA of B+ or higher
$60 \%$ Report Taking Physics
$60 \%$ Report Taking PreCalc




\section{Post Secondary Engineering Pipeline}

\section{Engineering Interest And Completion Has Remained Flat}

\section{Engineering Majors}

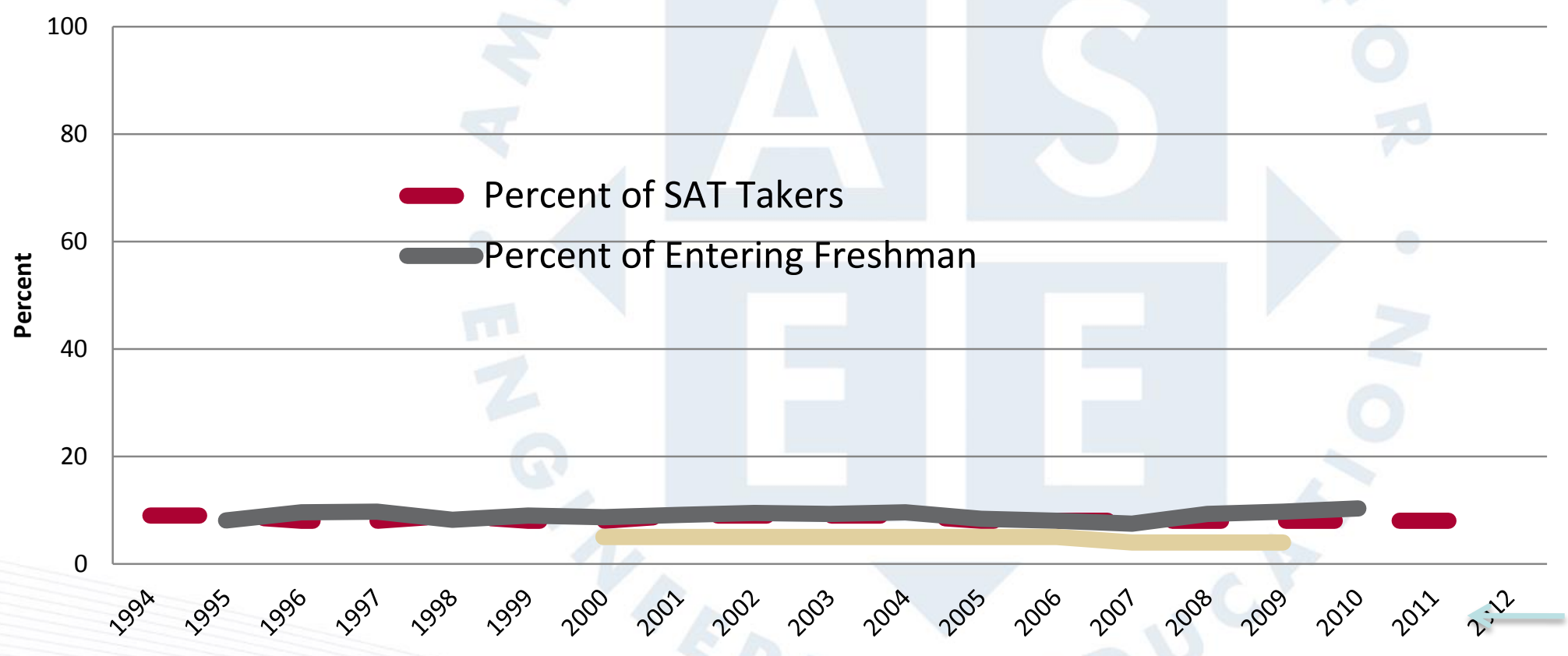

Nearly 30 years of Data 


\section{AP Exam Growth from Launch Year}

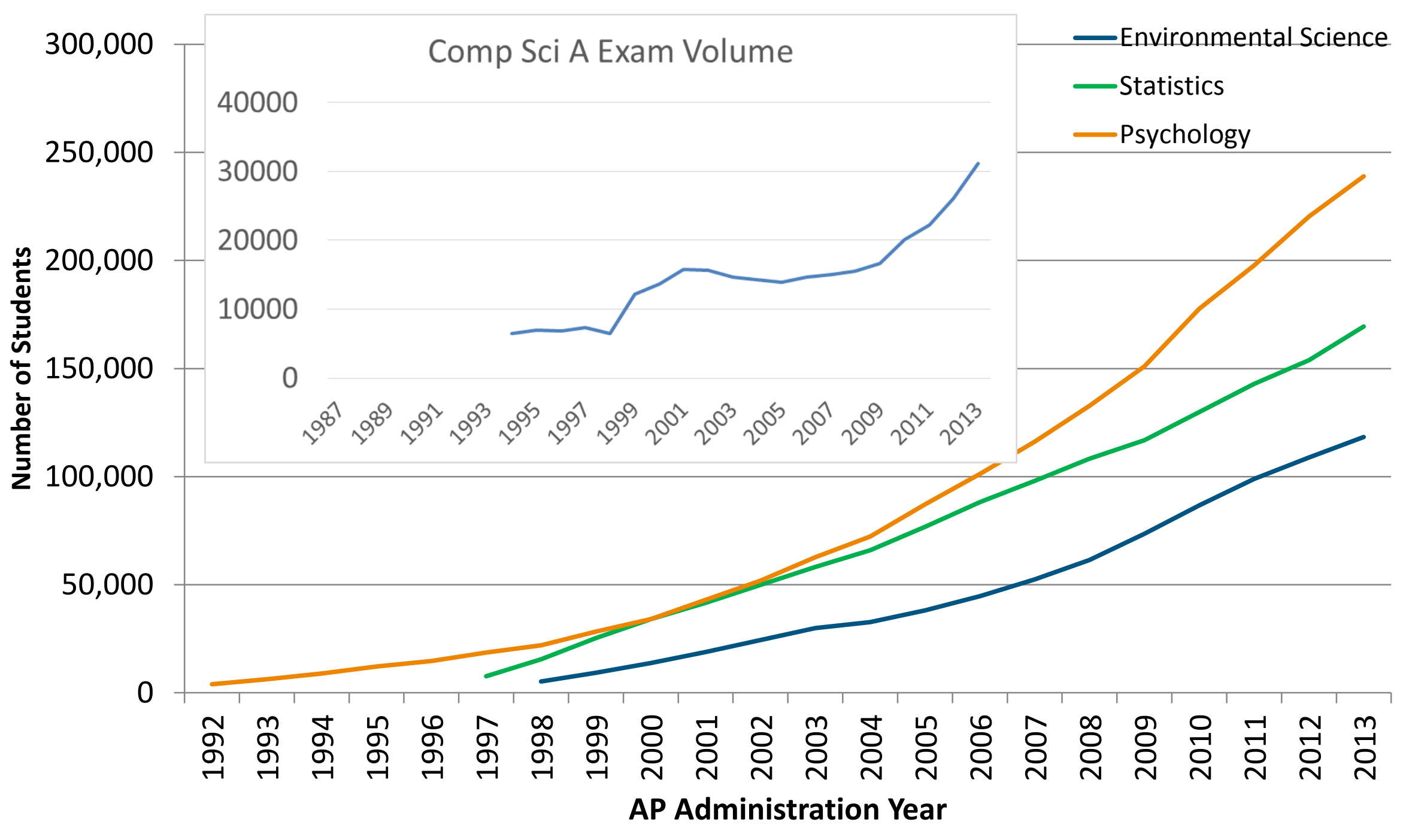




\section{Timeline of ASEE Engagement With College Board on AP in Engineering}

$\checkmark 2010 \quad$ Update to College Board on Engineering Design Project Portfolio Scoring Rubric EDPPSR Progress

$\checkmark 2011 \quad$ NSF PRIME Program Award on EDPPSR (UMD/UVA/PLTW)

$\checkmark 2013 \quad$ Meeting at College Board to discuss status of AP in Engineering (2/14)

$\checkmark 2013$ Session: "NGSS and Engineering" a EDI at Grand Hyatt in NYC (4/14-4/16 )

7 Questions asked with Clicker Responses-Auditi Chakravarty/Maureen Reyes

$\checkmark$ - What additional support would students need to get them to engineering?

$\checkmark$ - What would attract women and other underrepresented groups to engineering?

$\checkmark$ - What additional support would schools need to get them to engineering

$\checkmark$ - Percentage of schools with capacity for engineering (teachers, resources, etc.)

$\checkmark$ - What training would an engineering teacher need? (either existing teacher or practitioner)

$\checkmark$ - What alternative certification pathways exist for practitioners to teach engineering?

$\checkmark$ - What percentage of existing teachers would be interested in teaching engineering?

$\checkmark 2013 \quad$ Interest by White House OSTP on an AP in Engineering

$\checkmark 2013 \quad$ Survey of Engineering Deans, AP Teachers, Students-(10/16)

$\checkmark 2014$ Approval by Engineering Deans Council to Develop Curriculum (4/12)

$\checkmark 2014$ Commitment by College Board to fund Curriculum Development-6/14

$\checkmark 2015$ Appointment of Ms. LaTanya Sharpe to lead AP in Engineering under Mr. J. Williamson 


\section{ASEE/College Board AP in Engineering Survey Committee Members:}

- Darryll Pines, University of Maryland, College Park, Co-Chair

- James Aylor, University of Virginia, Co-Chair

- Nicholas Altiero, Tulane University

- Richard Benson, Virginia Tech

- Richard Brown, University of Utah

- Keith Buffinton, Bucknell University

- Lance Collins, Cornell University

- Peter Crouch, University of Hawaii

- Hesham El-Rewini , University of North Dakota

- Douglas Goering, University of Alaska

- Jeff Goldberg, University of Arizona

- Leah Jameson, Purdue University

- Thomas Katsouleas, Duke Unversity

- Kazem Kazerounian, University of Connecticut
- Louis Martin Vega, North Carolina State University

- Gary May, Georgia Institute of Technology

- David Munson, University of Michigan

- Paul Plotkowski, Grand Valley State University

- James Plummer, Stanford University

- Steven Schreiner, College of New Jersey

- Richard Stamper, Rose Hulman Institute of Technology

- Laura Steinberg, Syracuse University

- lan Waitz, MIT

- Greg Washington, University of California, Irvine

- Yaw Yeboah, Florida State University/Florida A\&M

- Yannis Yortos, University of Southern California 


\section{Course Title Interest}

$57 \%$ would like to see AP Introduction to Engineering

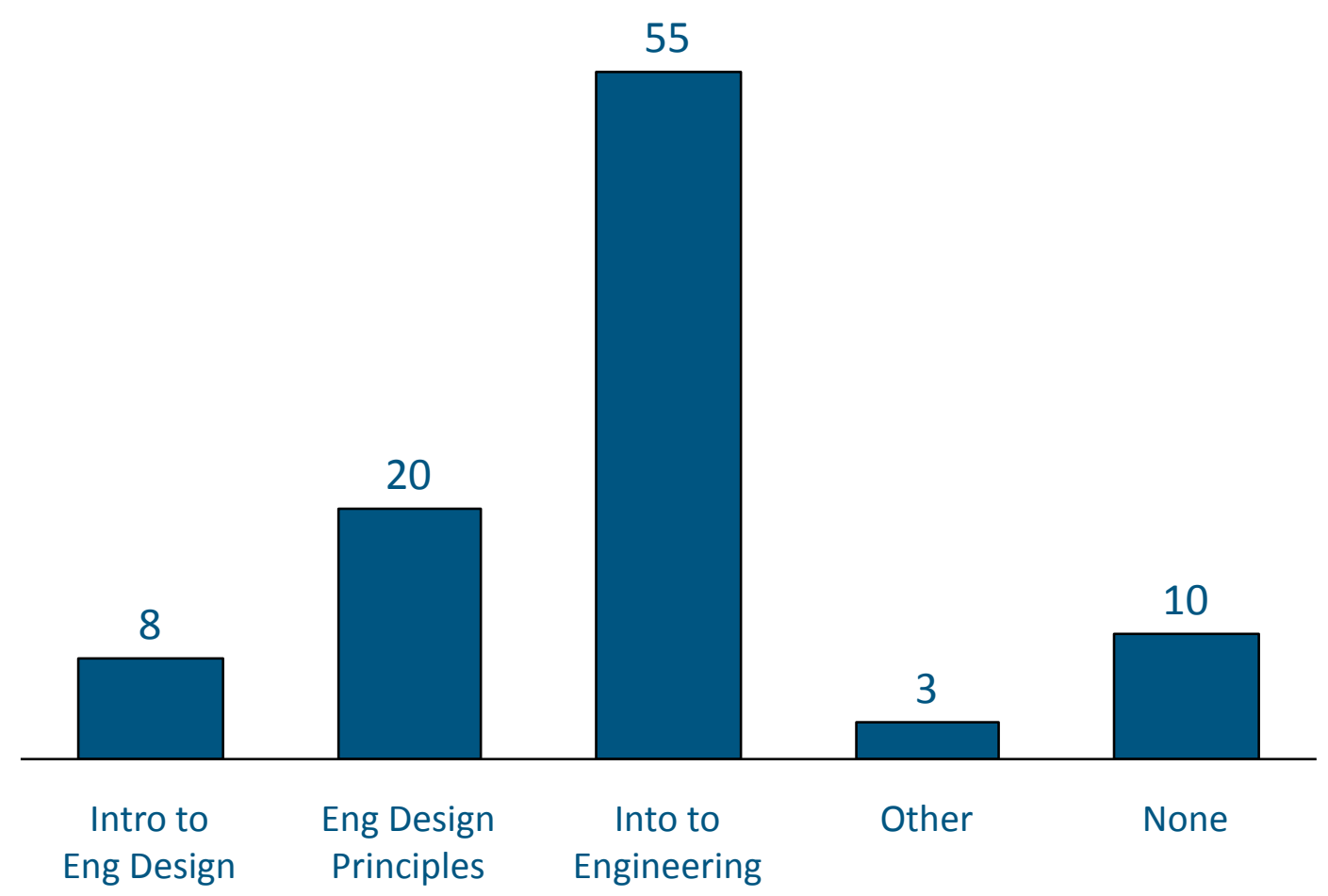

Engineering Enrollment by Course

\begin{tabular}{l|r|}
\hline Intro to Eng Design & 18,009 \\
\hline Eng Design Principles & 21,344 \\
\hline Intro to Engineering & 68,930 \\
\hline Other & 6,947 \\
\hline None & 16,134 \\
\hline
\end{tabular}




\section{How Open Would Your Institution Be To Allowing Students To}

Earn Credit Towards The Engineering Major?

\section{2\% Thought That Their Institution Would Be Extremely To Very Open}

75\% Thought That Their Institution Would Be Extremely to Very Open to Somewhat Open

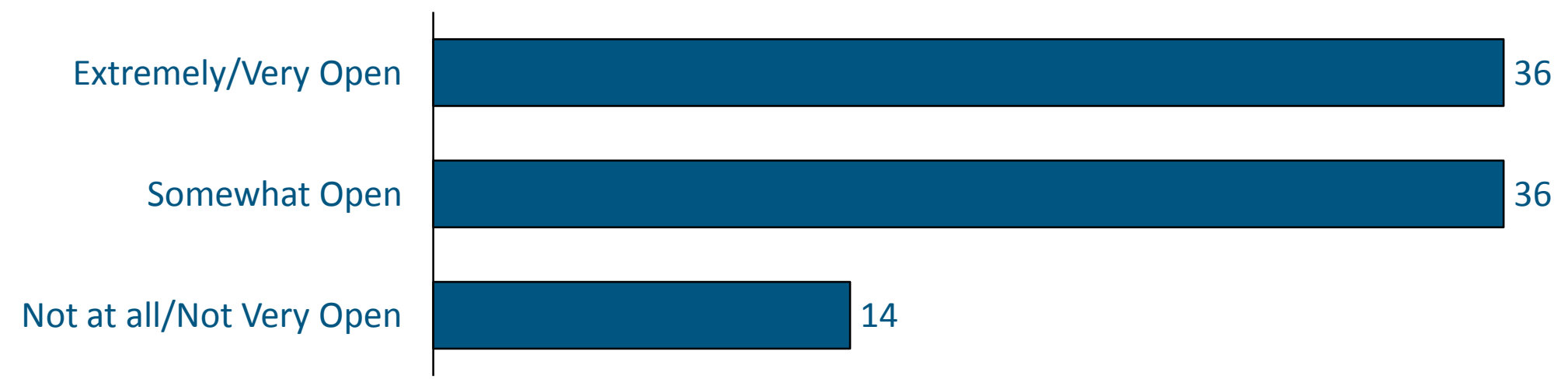



Indicating Commitment To Grant Credit/Placement For AP Engineering Program

\section{$54 \%$ Strongly to Somewhat Agree}

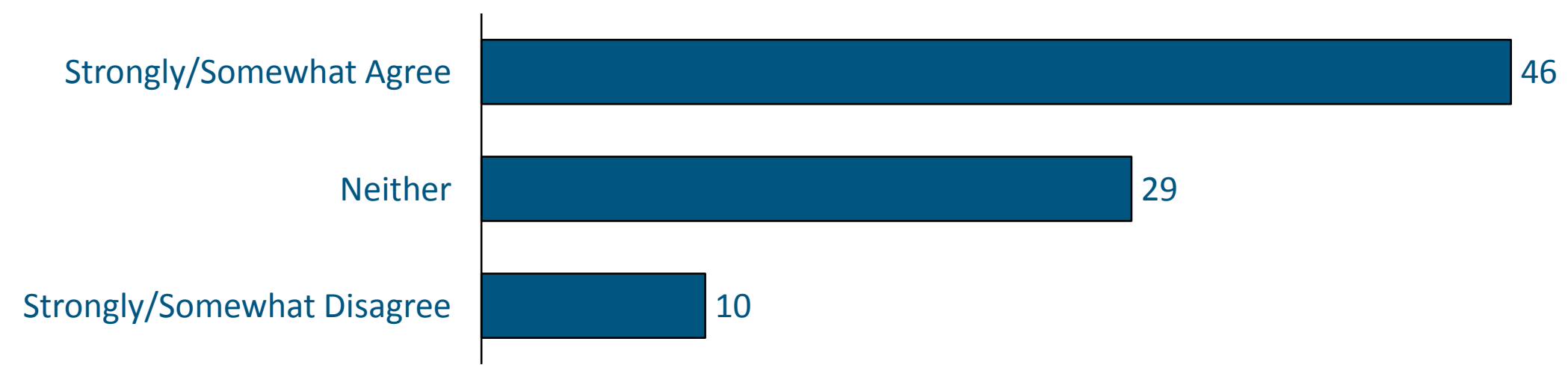




\section{ASEE EDC Approvals}

- Step 1: Seek approval from EDC Executive (April 2014)

- Committee to move forward with the Development of a joint ASEE/College Board Curriculum Committee

- Committee will develop framework and curriculum for either a course on

- Introduction to Engineering, or

- Introduction to Engineering Principles

- Step 2: Seek approval from EDC-Executive Committee and General Body that if course framework and curriculum are acceptable that colleges can grant both placement and credit in their engineering programs (Requires attestation of a majority of Engineering Deans).

- Place out of a course in Core engineering curriculum, or

- Use as elective on General Education/Core Requirement credit 


\section{Committees work to build AP Engineering}

Defines key concepts and big ideas

Synthesizes concepts and ideas and builds the framework

\section{Advisory Group \\ 15-20 Consultants \\ (HE, K-12, Industry, Government)}

\section{Curriculum Framework Group}

8 Consultants from different disciplines

(5 HE, $3 \mathrm{~K}-12$ ) 


\section{Curriculum Framework Development}

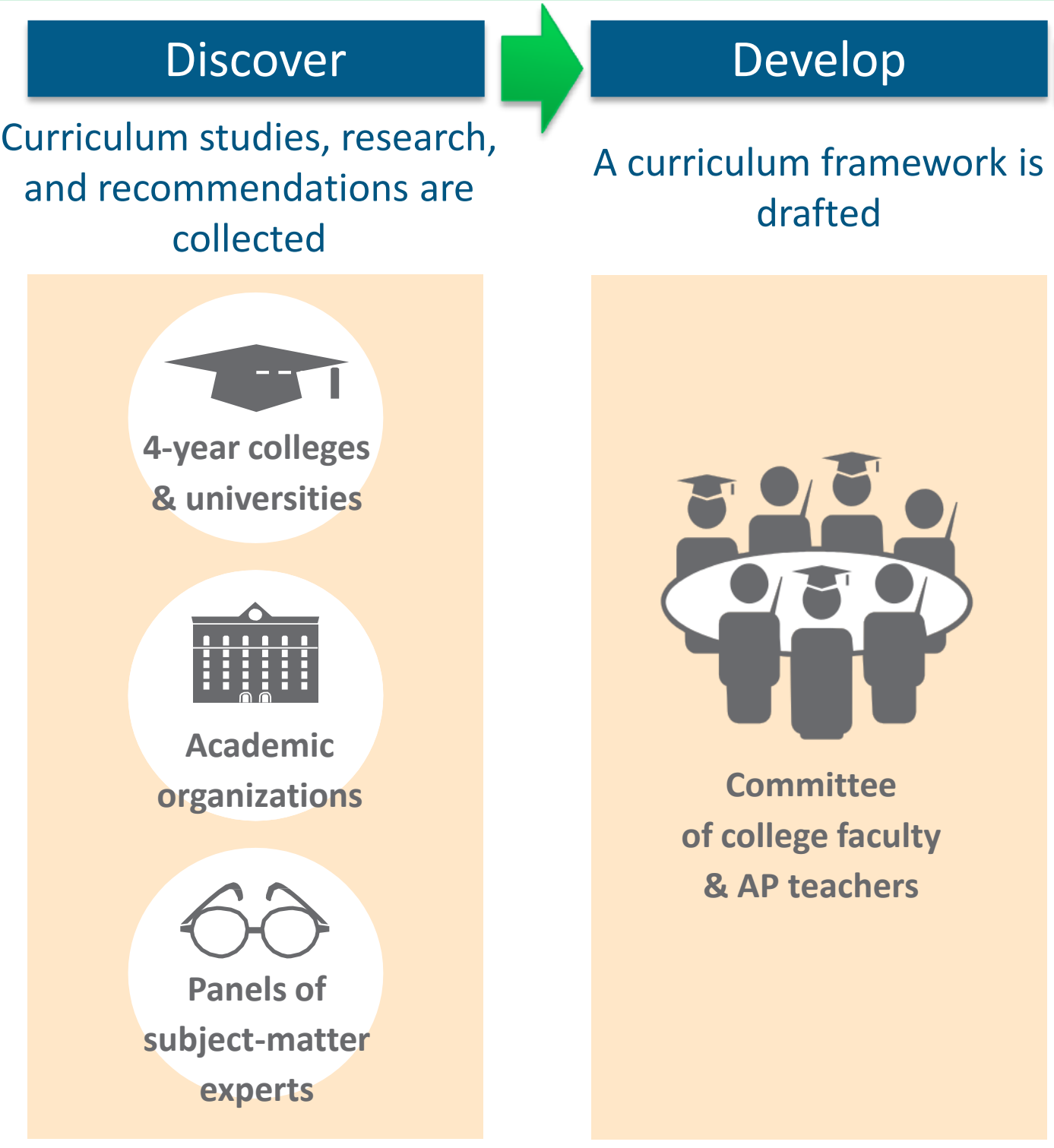

\section{Validate}

The curriculum framework is reviewed and verified

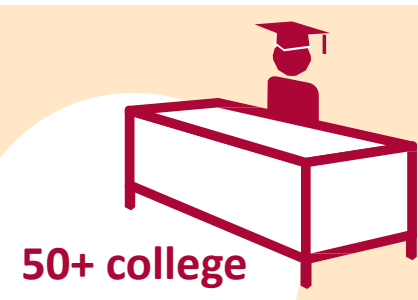
department chairs

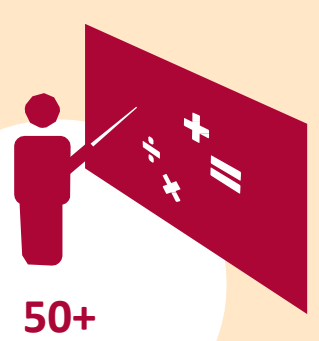

AP teachers 


\section{AP Engineering Advisory Committee}

AP Engineering Advisory Committee:

1) Darryll Pines, UMD, College Park

2) Dan Mote, NAE

3) Leo McWilliams, Notre Dame

4) Norman Fortenberry, ASEE

5) Norman Augustine, former LMC

6) Gary May, Georgia Tech

7) Jeff Goldberg, Univ. of Arizona

8) Ioannis Moallis (Yannis), Boston MOS

9) Ian Waitz, MIT

10) Louis Martin-Vega, NC State

11) Bonnie Dunbar, Univ. of Houston

12) Stan Little, NCR

13) Ann Spence, UMD, Baltimore County 


\section{AP Engineering CDAC Members}

1) Dan Frey, MIT

2) Roxanne Moore, Georgia Tech

3) Lynn Katz, University of Texas, Austin

4) Randy Weinstein, Villanova

5) *Elizabeth Parry, North Carolina State University

6) Angela Benjamin, Woodrow Wilson High School, Washington DC

7) Sharon Tomski, St. Thomas Moore High School, Milwaukee, WI

8) Stephanie Ogden, L\&N STEM Academy, Knoxville, Tennessee

\section{*ASEE K-12 Division Input:}




\section{AP in Engineering DRAFT Curriculum Framework}

\section{Overarching Goal of the AP Engineering Course.}

A successful AP Engineering student will confidently, creatively and collaboratively apply foundational concepts, use tools, and engage in processes used by all engineering disciplines to conceive, design, and communicate ethical solutions that protect, sustain, and delight individuals and society. 


\section{AP in Engineering DRAFT Curriculum Framework}

\section{Big Idea Themes}

- Big Idea 1: Processes (design, modeling, data, framing problems, problem-solving, stakeholders, communicating results, failure analysis and iterative process, collaboration (team work))

- Big Idea 2: Concepts (systems, balance, assumptions, uncertainty, open-ended or ill-defined problems, boundaries, dimensional analysis, input/output, spatial reasoning and visualization, equilibrium, stability, state and rate of change)

- Big Idea 3: Tools (technical and non-technical communication, regression, statistics and probability, risk assessment, resource management, communication/defending, justifying solutions, persuasion, collaboration (team work), project management, computer-aided and mathematical models, pencil \& paper tools)

- Big Idea 4: Engineering and Society (ethics, sustainability, Grand Challenges, different disciplines, interaction between different disciplines) 


\section{AP in Engineering DRAFT Curriculum Framework}

\section{Big Idea Learning Outcomes}

\begin{tabular}{|c|c|c|}
\hline $\begin{array}{l}\text { Enduring } \\
\text { Understanding } \\
\text { Enduring } \\
\text { understandings are the } \\
\text { long-term } \\
\text { generalizations that } \\
\text { specify what students } \\
\text { will come to } \\
\text { understand and } \\
\text { takeaway about the key } \\
\text { concepts in the course. } \\
\\
\text { Students will } \\
\text { understand that... }\end{array}$ & $\begin{array}{l}\text { Learning Objectives } \\
\text { The learning objectives } \\
\text { articulate what students } \\
\text { need to be able to do, } \\
\text { often linking to the } \\
\text { transfer goals. The } \\
\text { learning objectives will } \\
\text { become targets of } \\
\text { assessment for the AP } \\
\text { assessments. } \\
\text { Students will be skilled } \\
\text { at... }\end{array}$ & $\begin{array}{l}\text { Essential Knowledge } \\
\text { The essential knowledge } \\
\text { includes the facts and basic } \\
\text { concepts that a student } \\
\text { should know and be able to } \\
\text { recall in order to perform the } \\
\text { learning objective. } \\
\text { Committee members should } \\
\text { take care to constrain the } \\
\text { required knowledge to that } \\
\text { which is critical success in } \\
\text { sequent courses in the } \\
\text { discipline. } \\
\text { Students will know... }\end{array}$ \\
\hline
\end{tabular}




\section{AP in Engineering Course Options/Possibilities}

\section{CourseTitles....}

- Option 1: Introduction to Engineering Design (Not Considered)

- Option 2: An Introduction to Engineering

- Option 3: Statics

- Option 4: Engineering Survey Courses: Introduction to Electrical and Computer Engineering, etc. 


\section{Option 2:}

\section{An Introduction to Engineering}

- Engineering habits of mind, and basic elements of Engineering Design Process and Systems Thinking

- Grand Challenges are used to connect students to societal problems.

- Engineering analysis, visualization tools, and a

- Survey of various engineering disciplines

- All engineering disciplines... 
College Board would like to conduct another survey of Engineering Deans

Need at least 100 Deans to attest to placement and credit

- What would universities be most favorable to in terms of placement and credit?

- Option 2: Introduction to Engineering

- Option 3: Statics

- Option 4: Engineering Survey Course-e.g. Introduction to Electrical and Computer Engineering

- Credit or Placement Possibilities

- Core Engineering Curriculum

- Technical Elective

- General Education

- How many of you would be willing to attest to providing possible credit and placement?

- Seek your Full Cooperation to respond to the Survey and carefully examine your engineering curriculum to determine where credit/and or placemeint might be permitted. $\theta$ collegesoard 


\section{WHERE STATES STAND}

The Next Generation Science Standards were issued in April. Since then, eight states and the District of Columbia have adopted them.
"Lead state partners" in developing the Next Generation Science Standards

- States that have adopted the standards

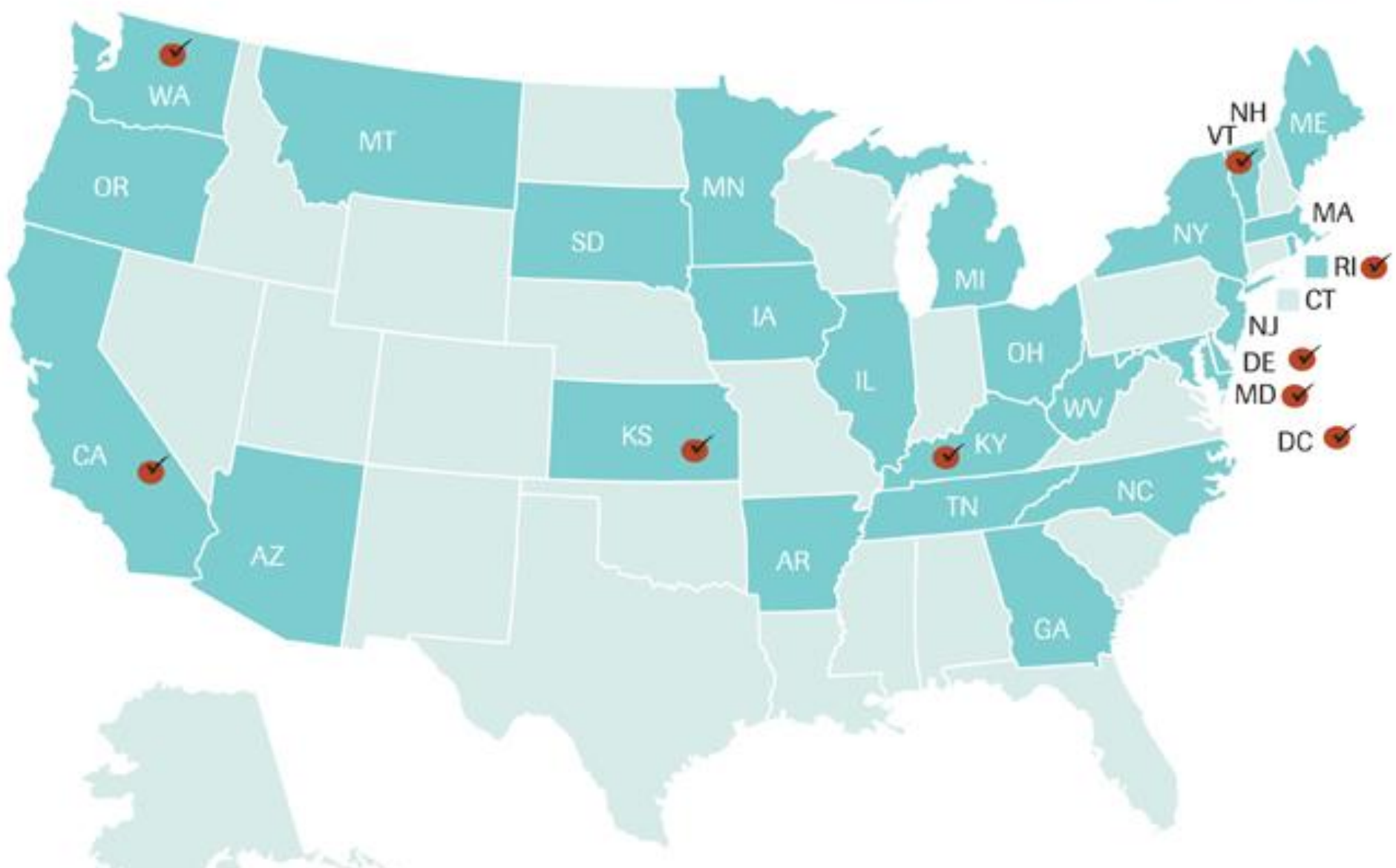

SOURCES: Achieve; Education Week 